\title{
In memory of a Maestro
}

Seldom the qualification of Maestro may find more appropriate use that in the case of Giuseppe Pellizzi, Emeritus Professor at the University of Milano, died suddenly last summer.

His contribution of enthusiasm and intelligence, his strong personality and commitment has deeply influenced at national and international level the agricultural engineering community and is death has left a gap that cannot be filled in all whose who have had the chance and the privilege of working alongside.

Thanks to his uncommon ability to attract and motivate young people, fascinating them with his intellectual dynamism and making them feel important and vital part of the Institute and its projects, he was a master of great charisma who led the training and scientific growth of numerous young researchers.

Many of them are continuing his work in various Italian universities, while others have played important roles in the world of business and institutions. It is enough to remember that 15 full professors of agricultural engineering area, many of whom have taken on roles of primary responsibility and prestige in academia and research, come from his school to understand how important his contribution to the development of the discipline was.

After graduating in Engineering from the Milan Polytechnic University in 1953 , he left with no regrets an already promising professional career to start work full-time as assistant professor in the Agricultural Machinery Department at the University of Milan, passing through all stages of the academic career ladder to become a full professor in 1968; he was awarded the title of Emeritus Professor in 1999.

Director of the Institute of Agricultural Engineering from 1964 to 1995 , he always carried out a policy of gradual and continuous process of growth that led the Institute itself to become one of the most important reference points of agricultural engineering at national and international level.

It is not easy to describe in short such an important figure along with the work of a scholar who, over more than fifty years left an indelible mark on the history of agricultural mechanization.

He had innumerable scientific and research interests, ranging from theoretical and experimental studies on tractors and processing machinery through to the definition of models for the rationalization of mechanization and optimization of work organization.

Promoting and encouraging large-scale projects that has always coordinated with uncommon energy and organizational capacity, in the second half of the ' $70 \mathrm{~s}$ was scientific director of the Agricultural Mechanization Project CNR PF which with the contribution of all major national research centres leading excellent results in terms of innovation.

Always aware to changing needs and circumstances, following the energy crisis of 1973, he was the first to understand the importance of a new approach to energy supply in agriculture, promoting and developing greater attention of the agricultural engineering world to the study of renewable energy sources.

Important and effective its contribution to the AIIA, in the ' $70 \mathrm{~s}$ as the first director of the newly Journal of Agricultural Engineering and then as active and dynamic President, in the period 1983-87, during which he worked with determination to get the recognition of the personalità giuridica of the Association.

As a convinced supporter of the notion that advanced research could not shrink back from a rigorous exchange of ideas, he always dedicat-

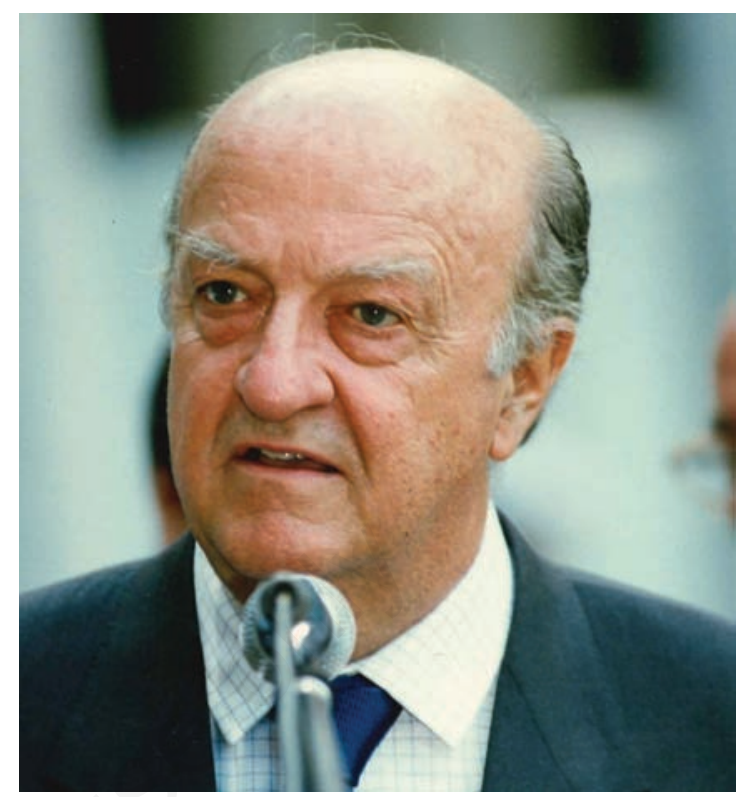

ed particular attention to internationalization and to exchanges at the most qualified world research centres.

Due to his professional impact but also, and even more so, to his personal charisma and outstanding ability in the promotion of worldwide networks he left a very deep mark in international Agricultural Engineering world.

In 1989, acting together with Federunacoma, he founded the Bologna Club, a prestigious association which brings together the leading world experts in agricultural mechanization with the purpose of promoting a harmonious development of the sector in various countries.

From 1991 to 1994, he was the chairman of the International Commission of Agricultural Engineering working actively for the revitalization of the association, which appointed him as honorary chairman as recognition of the particularly effective nature of his mandate.

He was co-founder of the European Community Club of Advanced Engineering in Agriculture (ECCAEA) that is now a strategic division of the EurAgEng, of which Giuseppe Pellizzi was also co-founder in 1992.

Pellizzi was a member and in leadership roles of many other major national and international scientific societies and academies. First of all the Accademia dei Georgofili, of which he was a member of the Academic Steering Committee from 1990 until 2008, president and honorary president of the CIOSTA, member of Accademie d'Agriculture de France, member of Russian Academy of Agricultural Science.

He was a senior adviser to the Italian ministries, FAO, UNIDO, EC, the National Research Council CNR and other organizations. The long list of other activities is not enough space. With the mixture of profound overview knowledge, imagination, visionary work proposals, winning organizational skills, impressive full assertiveness and sociability he achieved outstanding results that have been recognized by senior honours. The most important are singled out. 
Gold Medal of the Italian Minister of Science, 1978, Marchi Foundation Award 1981, Philip Morris International Award 1990, France Chevalier du Merite Agricole in 1992, Dr. H.C. University Godollo 1993, ASAE - Kishida International Award 1997, CIGR-UNACOMA International Award 1998, Dr. H.C. University of Ancona in 1998, DLG International Award 1999, Accademia dei Georgofili International Award 2003.

With Giuseppe Pellizzi the international agricultural engineer's family loses one of its most prominent leaders and father of her best-known school.

In addition to his academic achievements and his always goal-oriented leadership style we cannot forget his generosity, his collegial trust, his humour and sensitive humanity - as in almost fatherly outreach to less experienced colleagues.
A brilliant and charismatic teacher, and the author of the principal national textbooks on agricultural machinery, he taught generations of students who continue to recall with pleasure the educational value of his lessons.

With the passing of Giuseppe Pellizzi the national and international Agricultural Engineering Community has lost one of its most prominent leading personality and the world

All those who had the extraordinary opportunity to work closely with him will continue to hold in their thoughts and memories the teaching of his great human qualities, his wit and the friendly hospitality of his house.

Luigi Bodria 